University of Nebraska - Lincoln

DigitalCommons@University of Nebraska - Lincoln

Sociology Department, Faculty Publications

Sociology, Department of

2007

\title{
Adolescent Sexual Onset: An Intergenerational Analysis
}

Katherine Johnson

University of Nebraska-Lincoln

Kimberly A. Tyler

University of Nebraska-Lincoln, kim@ktresearch.net

Follow this and additional works at: https://digitalcommons.unl.edu/sociologyfacpub

Part of the Sociology Commons

Johnson, Katherine and Tyler, Kimberly A., "Adolescent Sexual Onset: An Intergenerational Analysis" (2007). Sociology Department, Faculty Publications. 50.

https://digitalcommons.unl.edu/sociologyfacpub/50

This Article is brought to you for free and open access by the Sociology, Department of at DigitalCommons@University of Nebraska - Lincoln. It has been accepted for inclusion in Sociology Department, Faculty Publications by an authorized administrator of DigitalCommons@University of Nebraska - Lincoln. 
Published in Journal of Youth and Adolescence 36 (2007), pp. 939-949; doi 10.1007/s10964-006-9165-z

Copyright (C) 2007 Springer Science+Business Media, LLC. Used by permission.

http://www.springerlink.com/content/104945/

Submitted September 13, 2006; accepted December 21, 2006; published online January 17, 2007.

\title{
Adolescent Sexual Onset: An Intergenerational Analysis
}

\author{
Katherine A. Johnson \& Kimberly A. Tyler \\ Department of Sociology, University of Nebraska-Lincoln, 711 Oldfather Hall, Lincoln, NE 68588-0324, USA
}

\begin{abstract}
Adolescents have begun to initiate sexual activity at increasingly early ages in the past few decades. Using a sample of 2,494 adolescents from the National Longitudinal Survey of Youth (NLSY97), structural and parental process variables were examined in the prediction of sexual onset. Results indicated that the age at which youth initiate sexual intercourse is related to the structural characteristics of their grandmothers and mothers, as well as puberty, gender, and race. There is support for partial mediation of the effects of these grandmother characteristics via mother characteristics and parental process. Results are discussed within the framework of the life course perspective and provide support for the importance of previous generations in the explanation of adolescent sexual behavior. Implications for families and adolescents are also addressed.
\end{abstract}

Keywords: sexual onset, adolescents, parental processes, intergenerational transmission

$\mathrm{O}$ ver the past several decades, adolescents in the United States have become sexually active at increasingly younger ages; by the age of $16,40 \%$ of females and almost $50 \%$ of males have had sexual experiences and by age 17, the percentage jumps to approximately 50 and $60 \%$ respectively (Steinberg, 2002). Additionally, current national estimates suggest that the median age of intercourse initiation is 16.9 years for boys and 17.4 years for girls (The Alan Guttmacher Institute, 2002). Definitions of what constitutes "early" sexual onset vary considerably in the literature. While some researchers define early sexual debut as having had sex prior to age 14 or 15 (Kowaleski-Jones and Mott, 1998; Mott et al., 1996; Rafaelli and Crockett, 2003), others, such as Longmore et al. (2004), define early sexual intercourse as that

Correspondence - Katherine A. Johnson

email: katiej2003@prodigy.net

Katherine A. Johnson, is a doctoral student at the University of Nebraska-Lincoln. Her research interests include the study of crime, gender, and high-risk youth using both qualitative and quantitative methodology.

Kimberly A. Tyler, is an associate professor in the Department of Sociology at the University of Nebraska-Lincoln. Her research interests include homelessness, child abuse and neglect, victimization, and high-risk behaviors among adolescents and youth. which occurs between ages 13 to 17. Other researchers do not give specific ages, but include grade levels instead; sex prior to high school graduation has been cited as "early" (Harvey and Spigner, 1995; Ream and Savin-Williams, 2005; Tubman et al., 1996). Thus, the literature indicates that what is considered "early" generally encompasses those individuals in junior high and/or high school.

Regardless of the way it is defined, early sexual onset is particularly concerning because of its association with numerous other risky sexual behaviors such as having a greater number of sexual partners, more frequent sexual activity, and older sexual partners (Durbin et al., 1993; Koyle et al., 1989). Further, individuals who engage in sexual intercourse at young ages are less likely to use effective contraception (Mosher and McNally, 1991), and are at higher risk for teenage pregnancy (O'Donnell et al., 2001) and for the contraction of sexually transmitted infections (Centers for Disease Control and Prevention, 2004) than those who initiate sexual activity at later ages.

Although numerous studies have demonstrated the importance of both structural variables (e.g., household composition, income) and parental process variables (e.g., attachment, closeness) on the onset of sexual activity (Lammers et al., 2000; Murry, 1996; Oman et al., 2005), very little research has examined how the timing of sexual debut may be reproduced across generations. As such, the purpose of 
the current study is to examine the extent to which characteristics of mothers and grandmothers affect the timing of adolescent sexual onset, and the extent to which these effects are direct or indirect, within the framework of the life course perspective (Elder, 1995, 1996).

\section{Theoretical perspective}

A life course developmental perspective, with its focus on social timing and linked lives, is useful for explaining how structural variables spanning three generations as well as parental process variables may be associated with the timing of sexual onset among adolescent males and females. The concept of social timing refers to how individuals may depart from social roles that are associated with age expectations and beliefs (Elder, 1995, 1996). For example, the timing at which adolescents initiate sexual onset may be influenced by what they view as acceptable based on their parent's behavior. For example, Kowaleski-Jones and Mott (1998) found that mothers who had an earlier mean age at first sex were likely to have children who initiated sexual activity at younger ages. Though based on univariate comparisons, these results provide support for the intergenerational transmission of sexual activity. In a similar study, Mott et al. (1996) also found support for this intergenerational linkage based on multivariate analyses. That is, children who had become sexually active prior to age 14 had mothers who had an earlier age of first sexual onset. This relationship held for both boys and girls (Mott et al., 1996). The authors of both studies conclude that the sexual behavior of mothers is subsequently associated with the sexual behavior of their offspring.

The social timing of sexual debut is also tied to linked lives, which refers to the embeddedness of social relationships with kin across the life span (Elder, 1995, 1996). This means that the patterns that exist in relationships with others are closely linked. Thus, the timing of first sexual intercourse and child bearing in previous generations are likely to be influential across time. That is, if mothers (G2's) were young when they began childbearing, they likely initiated sexual activity at an earlier age. As such, we would expect their children, the adolescents (G3's) in the current study, to have the same experiences. Similarly, the behavior and interactions of grandmothers (G1's) are likely to be associated with that of their daughters (G2's), and that the G1's characteristics may directly or indirectly affect G3's current behavior. Finally, because social relationships with kin tend to be embedded across time, if early family interaction patterns were negative and marked by lower levels of monitoring and higher rates of rejection, these processes are expected to be associated with the social timing of adolescent sexual onset.

\section{Review of the literature regarding correlates of sexual onset}

Demographic and structural correlates of sexual onset

In the United States, females and white youth tend to initiate sexual activity at later ages than males and those of other racial and ethnic groups (Grunbaum et al., 2004; Miller et al., 1997; Santelli et al., 2000). Additionally, socioeconomic status (SES) and parental education have often been found to be negatively related to age of sexual onset. Youth who reside in families of higher SES and those whose parents are more educated are likely to have initiated sexual intercourse at later ages according to a number of longitudinal studies of young people ranging in age from birth to 22 years old (Lammers et al., 2000; Miller et al., 1997; Santelli et al., 2000; Udry et al., 1995). Another socio-structural aspect of the family is household composition. Research on youth ranging in age from 13 to 21 (both cross-sectional and longitudinal) has shown that youth who live in non-intact families are likely to have initiated sexual activity at earlier ages than those living with both biological parents (Lammers et al., 2000; Murry McBride, 1996; Oman et al., 2005; Santelli et al., 2000). Finally, both longitudinal (French and Dishion, 2003; Miller et al., 1998; Whitbeck et al., 1999) and cross-sectional (Flannery et al., 1993) research on youth ranging in age from 10 to 17 have found that those who have gone through puberty are likely to have engaged in sexual activity at earlier ages.

Prior researchers, in their pursuit for correlates of adolescent sexual behavior, have often cited early maternal childbearing as a risk factor for early sexual onset among adolescents. Among a sample in New Zealand, mothers who began childbearing at age 19 or younger were significantly more likely to have daughters who initiated sexual intercourse prior to age 16 (Paul et al., 2000). Additionally, both male and female children of teenaged mothers in the United States were found to have more frequent sex at ages 16-17 when followed longitudinally (Ensminger, 1990), a well-documented correlate of early sexual activity (Durbin et al., 1993; Koyle et al., 1989). Finally, female children of teen mothers were more likely to become teen mothers themselves both in Great Britain (Manlove, 1997) and in the United States (Maynard, 1996). Because the characteristics and behaviors of mothers are associated with the sexual behavior of their offspring, it is also possible that the sexual debut of adolescents is additionally associated with, either directly or indirectly, the characteristics and behaviors of their grandmothers. Very little research, however, has examined adolescent sexual activity within the context of an intergenerational analysis. 
Parental processes as correlates of sexual onset

Beyond demographic and structural correlates of sexual onset, family interaction has often been found to be associated with the timing of sexual onset. Parental monitoring, defined as, "parental awareness of what the[ir] child is doing and of his or her whereabouts" (Longmore et al., 2001, p. 324), is an aspect of parental process that has been researched a great deal. Rodgers (1999) suggested that parental monitoring might lead to less risky sexual behavior among adolescents in different ways. Parental monitoring, first, "conveys to teens that parents care and are concerned" (p. 106). Parents who monitor and show concern for their children convey to them that they matter. According to Rosenberg and McCullough (1981), "mattering" is important to individuals and especially to adolescents. This perception of being cared about, it has been argued, may lead adolescents to participate in less risky sexual behavior. Monitoring may also lead to less risky sexual behavior among adolescents because parents are regulating their children's dating partners and the amount of opportunities they have to engage in sexual activity (Rodgers, 1999). Overall, researchers tend to agree that greater parental monitoring is related to delayed onset of intercourse among American young people ranging in age from 9-20 regardless of whether the research is cross-sectional (Danziger, 1995; Ku et al., 1993; Romer et al., 1994) or longitudinal (French and Dishion, 2003; Capaldi et al., 1996).

In addition to monitoring, family rejection or a lack of closeness with one's family has also been found to be a correlate of adolescent sexual behavior in much of the research on American families. Indeed, Whitbeck and colleagues (1999) found that a relatively higher level of maternal rejection was related to a higher probability of early intercourse over time regardless of gender. Lauritsen (1994), in a longitudinal study of 11 to 17 year olds, found greater family attachment to be related to a lower probability of sexual initiation among White males, but not among females or Black males. Similarly, Benda, and Corwyn (1999) found that greater familial attachment was related to less adolescent sexual activity among a poor rural sample of young people. Finally, Ream and Savin-Williams (2005) in their longitudinal study, found that youth who are less close to their parents are likely to share fewer activities with them and be more problem focused which results in an increased likelihood of sexual onset. Because, according to the life course perspective, what happens early in life can have persistent effects on later life outcomes and behaviors, it is our contention that maternal monitoring and rejection may have profound effects on adolescent sexual behavior.

\section{Hypotheses}

Social timing and linked lives identify ways in which early family patterns of mother's and grandmother's own behavior may be linked to the timing of subsequent adolescent behavior. As such, we hypothesize that grandmothers (G1's) who had completed a greater number of years of education, grandmothers (G1's) who were older when they gave birth to the responding parent (G2), and grandmothers who lived with the biological father of their child (G2), will have grandchildren (G3) who are likely to have initiated sexual intercourse at older ages. This relationship may be direct or indirect via mother characteristics (mother's education, mother's childbearing age, and whether the mother lived with the target youth's biological father) or through parental process (monitoring and rejection).

\section{Method}

Data

Analyses were based on data from the National Longitudinal Survey of Youth 1997 (NLSY97). The NLSY97 is the newest assessment in the series of National Longitudinal Surveys and is a representative sample of people living in the United States in 1997 who were born between 1980 and 1984 (Center for Human Resource Research, 2002a). In round 1 , when the youth were 12 to 16 years of age, both the youth themselves, as well a parent or guardian also residing in the household were interviewed. Because parental/guardian interviews were only attained in approximately $90 \%$ of the target youth (Center for Human Resource Research, 2002a; Section 2.2, Table 2), the sample was restricted to youth for whom this data were available. Parents were not only asked about the attitudes and behaviors of their children, but about their own lives as well. In subsequent years, data were collected annually from youth only. The sampling design of the NLSY97 features an oversample of Hispanic/Latino and Black youth, which allows researchers to analyze behaviors and experiences across racial/ethnic groups.

\section{Sample}

The sample employed in the current analyses included 2,494 youth who were 12-13 years of age as of the date of the interview in 1997. This age group was chosen because it represents the youngest respondents available in the NLSY97, and thus, those least likely to have already initiated sexual intercourse. Because the inclusion of more than one target youth within the same household violates assumptions of independence, in the event of sibling pairs within the same household (less than $4 \%$ of the sample), one respondent from each household was randomly selected for inclusion in the final sample (cf. Chapple et al., 2005; Rafaelli and Crockett, 2003). No variable had missing data on more than $12 \%$ of responses with the exception of income (an NLSY created variable) which was missing on $16 \%$ of responses. These missing data were imputed dur- 
ing the analyses using an EM algorithm in Mplus. For more information on this procedure, see the Mplus users guide (Muthén and Muthén, 2004).

\section{Measures}

Gender was coded so that $0=$ male and $1=$ female. Racial category was assessed using two variables: Black $(0=$ NonBlack, $1=$ Black $)$ and Hispanic $(0=$ Non-Hispanic, $1=$ Hispanic). Contrast coding was employed in the analyses with Non-Black/Non-Hispanic as the omitted category. Income was measured with a variable created by the NLSY data analysts that compared the total household family income in 1996 to the federal poverty level for that year (Center for Human Resource Research, 2002b, Appendix 5). The resulting variable was then collapsed to account for skew. Response categories ranged from 0 indicating that the respondent's family income was below poverty level; to 9 indicating that the respondent's income is 10 times greater than the poverty level. Additionally, age was assessed in 1997 and ranged from 12 to 13, and was controlled for in all analyses.

A single dichotomous variable was created to account for puberty status among both male and female youth in 1997. It was explained to boys that, "People reach puberty at different ages. Signs of puberty for males include physical changes such as developing pubic or facial hair, or the voice cracking or lowering." Boys were given four possible response options regarding the progress of these changes ranging from they "have not yet begun" to they "seem completed." Girls were simply asked whether they had ever had a menstrual period. In order to combine these two items into a single gender-neutral variable, the male puberty variable was dichotomized so that a score of zero indicated that the pubertal changes had not yet begun or had barely started, and a score of one indicated that the changes were definitely underway or seemed complete. Although we cannot be certain that these measures represent exactly the same level of pubertal development for both genders, the proportion of boys relative to girls who have reached puberty according to the measure (i.e., more females than males) is consistent with previous research (Haynie and Piquero, 2006; Underwood and Van Wyk, 1992).

A series of variables regarding the experiences of the target youth's mother as well as their grandmother were assessed in order to explore the intergenerational transmission of structural and behavioral traits. Information about the target youth's grandmothers was gathered from the parental assessment portion of the 1997 data. In each sampled household, a parent or guardian was selected to answer questions about themselves and all children between the ages of 12 and 16 residing in their household. This responding parent was selected based on a hierarchical list of preferred respondents. Biological mothers are ultimately preferred; however, when they were not available, an ordered list of alternate respondents was followed (see Cen- ter for Human Resource Research, 2002a, Figure 1 for a preferred respondent list). A dummy variable was created to assess whether the responding parent was a biological mother (approximately $84 \%$ of the current sample) or someone else, and was included in the analysis to control for potential bias.

Grandmother's (G1's) education was assessed in 1997 by asking the responding parent to report the highest grade completed by their mother. Response categories ranged from $0=$ none to $7=$ graduate or professional degree. Grandmother's (G1's) age at the birth of the responding parent (G2) was calculated by subtracting the year G1 was born from the year that G2 was born. Additionally, the family structure of the mother (G2's) childhood home was assessed through data gathered in 1997. Responding parents were asked, "Did you live with both biological parents from birth until age 14?"

In addition to examining the experiences of the target youth's grandmothers (G1), the experiences of the target youth's mothers (G2) were also assessed. The educational attainment of mothers (G2's) was assessed with a variable created by the NLSY data analysts. Possible values ranged from $0=$ no schooling to $20=$ eight years in college or more. A variable created by the NLSY data analysts was also employed to assess the age at which the mothers (G2's) gave birth to their first child. This variable is measured with age in years. Additionally, the family structure of the adolescent's (G3's) childhood home is assessed in 1997 via a variable created by the NLSY analysts. The created variable was dichotomized and possible responses were $1=$ the target youth (G3) lived in a household with both biological parents at age 12, and $0=$ G3 lived in a household with other than both biological parents.

Additionally, two parental process variables, from data gathered in 1998, assessed the way the target youth's families functioned on a daily basis. Youth reported maternal monitoring was measured with an NLSY created variable based on four items which asked children how much their residential mothers (G2's) knew about their friends, their friends' parents, where they were when they were not home, and their school experiences. Responses ranged from $0=$ knows nothing to $4=$ knows everything. The responses to the items were summed resulting in a range of 0 to 16 with higher scores indicating greater maternal monitoring. The NLSY data analysts report an alpha of .71 for the total sample (Center for Human Resource Research, 2002b, Appendix 9) and the reliability was slightly higher among the current sub-sample (alpha $=.72$ ).

The final independent variable, measured in 1998, was youth reported maternal rejection. This variable was based on three items that asked youth (G3) how often their residential mother (G2) criticized them or their ideas, blamed them for her problems, and made plans with them and later canceled. Response categories ranged from $0=$ never to $4=$ always. The items were highly correlated $\left(r^{\prime}\right.$ s ranged from .27; $p \leq .01$ to $.36 ; p \leq .01$ ), the alpha reliability coefficient was .58 (analyses showed that the reliability would 
be worsened by the omission of any of the items), and the items loaded strongly onto a single factor. A mean scale was created.

The dependent variable, age of sexual onset, is a composite variable that includes data from 1998, 1999, 2000, 2001, and 2002. Each year after the youth reached the age of 14 , they were asked a series of questions regarding their sexual experiences. After reaching the appropriate age, youth are asked, "Have you ever had sexual intercourse, that is, made love, had sex, or gone all the way with a person of the opposite sex?" in each wave. A negative answer led to an automatic skip, and the youth received no further questions about sex during that wave. A positive answer led to more detailed questions about their sexual experience such as how old they were the first time they had sexual intercourse. Although youth continued to receive questions about sexual experiences in each following year, after the initial round in which the youth reported sexual activity, the age of sexual onset was not asked again. Because of this skip pattern in the survey design, a single item variable measuring age of onset from the 2002 assessment was not possible, and a more complex variable had to be created. Data from each wave were thus used to construct a variable measuring the age of sexual onset. The resulting variable had values of: $0=$ had sex for the first time at age 13 or younger, $1=$ had sex for the first time at age 14, $2=$ had sex for the first time at age 15, $3=$ had sex for the first time at age 16, $4=$ had sex for the first time at age 17-18, and $5=$ youth had never had sex. Thus, a higher score indicated a later age of sexual onset with the highest score (5) indicating that the youth had delayed the onset of intercourse longer than the rest of the sample, as evidenced by the fact that they remained virgins as of the 2002 interview. Although some researchers have found inconsistencies in the reporting of the age of sexual onset (Upchurch et al., 2002), other research has found that youth reports regarding the age of onset are reliable (Hearn et al., 2003).

\section{Results}

\section{Sample characteristics}

The final sample included 2,494 youth who were $12-$ 13 years old in $1997(\bar{X}=12.59)$. The sample was approximately $48 \%$ female, $25 \%$ Black, $21 \%$ Hispanic, $54 \%$ nonBlack/non-Hispanic, and had an average total household income of approximately two times the federal poverty level in 1996. Additionally, approximately $64 \%$ (61\% of males and $67 \%$ of females) of the target youth (G3) had reached puberty by age 12-13 in 1997. This is consistent with research that finds that males tend to reach puberty at older ages than females (Haynie and Piquero, 2006; Underwood and Van Wyk, 1992). On average, G1s had completed less than a high school education $(\bar{X}=2.51)$, had given birth to G2 at the age of 26.06, and $72 \%$ had provided an intact family for G2. Among the G2's, the average num- ber of years of education completed in 1997 was 12.59 indicating that G2's tended to have attained their high school degree and some post high school education, G2's began childbearing at the age of 22.89 , and $46 \%$ had provided an intact family for G3. With regard to parental process, youth (G3) reported an average monitoring score of 10.03 and a rejection score of .76 indicating a moderate level of monitoring and a low level of rejection. Finally, on average, youth in the sample scored 2.95 on the age of sexual onset variable indicating that most youth were approximately 16 years old the first time they had sex, which is similar to the national average.

In the current study, we employ path analysis using maximum likelihood estimation in Mplus (Muthén and Muthén, 2004) to investigate correlates of the timing of sexual onset (See Figure 1). A fully recursive model was tested in order to investigate the longitudinal effects of grandmother and mother characteristics as well as family process variables on the age of sexual onset among a sample of youth. It was expected that youth who had grandmothers who were more educated, gave birth at later ages, and who lived with the biological father of their child (G2) would initiate sexual intercourse at later ages. This relationship, however, was also hypothesized to be indirect via mother characteristics (mother's education, mother's age at first birth, and whether the mother lived with the target youth's biological father) and/or family process variables (monitoring and rejection).

Results for the path analysis in Figure 1 (only significant paths shown), revealed that grandmothers who had higher levels of education $(\beta=.58)$, who were older when they gave birth to G2 $(\beta=.02)$, and who lived with G2's biological father $(\beta=.42)$ were likely to have had daughters with significantly higher levels of education. Grandmothers who had higher levels of education $(\beta=.19)$, who were older when they gave birth to G2 $(\beta=.04)$, and who lived with G2's biological father $(\beta=1.63)$ were likely to have daughters who significantly delayed childbearing. Similarly, grandmothers who were older when they gave birth to G2 $(\beta=.00)$ and who lived with G2's biological father $(\beta=.09)$ were significantly more likely to have daughters (G2) who lived with the biological father of their child (G3). Grandmothers who lived with G2's biological father were likely to have daughters (G2) who monitored their child (G3) more frequently $(\beta=.52)$ and rejected their child less frequently $(\beta=-.09)$.

Grandmothers who had a greater level of education $(\beta=.09)$ were likely to have grandchildren (G3) who were significantly older at the time of sexual onset. Mothers (G2) who were older at first birth $(\beta=.04)$ and who lived with G3's biological father $(\beta=.58)$ were likely to have children (G3) who initiated sexual intercourse at significantly later ages. Finally, mothers (G2) who monitored their children (G3) more frequently $(\beta=.05)$ and rejected them less frequently $(\beta=-.20)$ were likely to have children who initiated sexual intercourse at significantly later ages. 


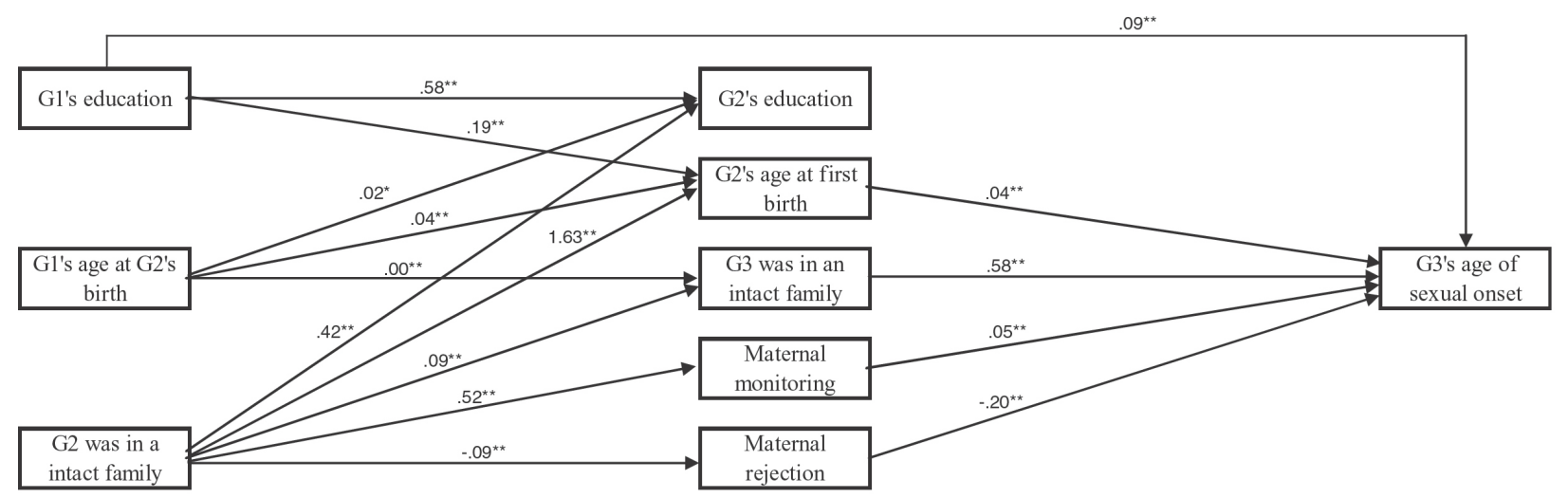

Figure 1. Path analysis $(n=2,494)$. Note: Standardized coefficients can be greater than one (Jöreskog, 1999)

Regarding the control variables, youth whose biological mothers were the responding parent were likely to have mothers who were significantly more educated $(\beta=.42)$, to have lived in intact families at age $12(\beta=.15)$, and to have been more frequently monitored $(\beta=.58)$. Youth who were 13 years old in 1997 were likely to have experienced significantly less frequent maternal monitoring $(\beta=-.26)$ than their 12 year old peers. Females were more frequently monitored $(\beta=.64)$ and initiated sexual intercourse at older ages $(\beta=.32)$ than males. Black youth were likely to have had mothers who began childbearing at younger ages $(\beta=-1.58)$, to have lived with someone other than both biological parents at age $12(\beta=-.29)$, and to have initiated sexual intercourse at younger ages $(\beta=-.34)$ than white youth. Hispanic youth were likely to have mothers who were less educated $(\beta=-1.59)$ and who initiated childbearing at younger ages $(\beta=-.71)$ than white youth. Youth from families with higher incomes were likely to have mothers who were more educated $(\beta=.47)$, who gave birth to their first child at older ages $(\beta=.67)$, and to have lived with both biological parents at age $12(\beta=.06)$.

In addition to the direct effects presented above, a number of indirect effects were significant. Although grandmother's level of education was directly associated with the age of sexual onset among the respondents, it was indirectly associated via mother's age at first birth $(\beta=.01)$ as well. Grandmothers who were more educated were likely to have daughters who delayed childbearing; when they did bear children, these children were likely to delay the initiation of sexual intercourse. Despite the fact that grandmother's childbearing age was not directly associated with G3's age of sexual onset, the effect was indirect via age of mother at first birth $(\beta=.00)$, and whether G3 lived with both biological parents at age $12(\beta=.00)$. More specifically, grandmothers who were older when they gave birth to G2 were more likely to have daughters (G2) who delayed childbearing and who later provided intact families for the children they did have (G3); these children, in turn, were likely to have delayed sexual onset. Additionally, whether grandmothers (G1) lived with their daughter's
(G2) biological father was significantly associated with the timing of sexual onset among their grandchildren (G3) via mother's age at first birth $(\beta=.06)$, whether mothers lived with their child's biological father $(\beta=.05)$, as well as maternal monitoring $(\beta=.02)$ and rejection $(\beta=.02)$. In other words, mothers (G2) who resided in an intact family until age 14 were likely to have delayed childbearing, but when they did have a child, they were likely to have lived with their child's biological father, and to more frequently monitor and less frequently reject their child; in turn, these children (G3) were likely to delay sexual onset.

\section{Discussion}

Overall, the results of the path analysis indicated that grandmother characteristics as well as mother characteristics and parental process are important for the development of adolescent sexual onset. Especially interesting findings emerged with regard to the indirect effects of grandmother characteristics. Results showed that grandmothers who were more educated tended to have grandchildren who delayed sexual onset; this relationship was both direct and indirect via the age of mothers at the birth of their first child. It is possible that grandmothers who are more educated are better able to articulate to their daughters (G2) the dangers of unprotected sex, and the virtues of delaying childbearing until they are older. Past research has shown that mothers who are more educated are likely to have children who delay intercourse initiation until later ages (Miller et al., 1997; Santelli et al., 2000; Udry et al., 1995). In turn, mothers who delay inter-course (and by default, delay childbearing) are likely to have children who delay intercourse as well (Paul et al., 2000).

Despite the fact that grandmother's childbearing age did not have a direct effect on adolescent sexual onset; it remained an important correlate indirectly via mother's childbearing age and whether adolescents lived with both biological parents. Results showed that grandmothers who gave birth at older ages had daughters (G2's) who also gave birth at older ages, which in turn was associated with de- 
layed sexual onset among G3's. This is consistent with previous research that has found that children of teen mothers are likely to become sexually active at younger ages (Paul et al., 2000), and to become teen parents themselves (Manlove, 1997; Maynard, 1996). It is likely that norms are passed down from mother to child such that those who believe that it is important to delay childbearing are likely to impress upon their children that they should postpone this event as well. Additionally, grandmothers who gave birth at older ages were likely to have daughters (G2's) who provided intact families for their own children (G3's). This in turn was associated with the delayed sexual onset among the target youth in the sample. Perhaps grandmothers who were older when they gave birth were also more established, in stable relationships, and were able to provide an intact family for their daughter (G2). Indeed, in the current analyses, grandmother's childbearing age and whether they provided an intact family were positively correlated $(r=.16)$. G2's who grew up in intact families were then likely to have had children who were older at the time of sexual debut. This is supportive of previous research that has shown that individuals who lived in intact families are likely to delay intercourse (Lammers et al., 2000; Murry, 1996; Oman et al., 2005; Santelli et al., 2000).

The final grandmother characteristic, whether grandmothers provided intact families for their daughters until they were 14 years old, was related to sexual onset via four different variables. First, the mothers in the sample who lived with their biological fathers until age 14 were likely to delay childbearing, and mothers who delayed childbearing were likely to have children who delayed the onset of sexual intercourse. This finding supports previous research (Manlove, 1997; Maynard, 1996; Paul et al., 2000). Next, mothers who lived with both of their biological parents until age 14 were likely to provide the same type of family structure for their own child; and G3's who lived in an intact family at age 12 were likely to have delayed sexual debut. Mothers who grew up in non-intact families were likely to replicate this family composition in their own lives and thus their children were more likely to have lived in a single parent home or reconstituted family setting at age 12 . This more proximal family structure experienced by G3's then had a direct effect on the age of sexual onset. The intergenerational transmission of family structure is a common finding in the literature (Amato, 1996; Bumpass et al., 1991). Finally, mothers who lived with both biological parents until they were 14 years of age were likely to spend more time monitoring and less time rejecting their children; their children, in turn, were likely to delay sexual debut. This is consistent with previous research that finds that youth who are in closer relationships with their parents and who are monitored more frequently are likely to delay the onset of sexual intercourse (Capaldi et al., 1996; Danziger, 1995; French and Dishion, 2003; Ku et al., 1993; Romer et al., 1994). It is clear from the current findings that the family structure within which G2's grew up is important in the explanation of the age of sexual onset among youth in this sample. Although the family structure provided to the mothers (G2) by the grandmothers is not directly related to sexual onset, it was nonetheless associated indirectly via mother characteristics and family process.

In addition to the importance of grandmother characteristics, a number of other factors contributed significantly to the explanation of the timing of sexual debut among the youth in the sample. Females, white youth, and those who had not reached puberty were likely to have had significantly later sexual onset when compared to males, black youth and those who had not reached puberty in 1997. This is consistent with previous research that has found that males, those of non-White racial and ethnic groups, and those who have reached puberty tend to initiate sexual intercourse at younger ages than females, Whites, and those who have not reached puberty (Flannery et al., 1993; French and Dishion, 2003; Grunbaum et al., 2004; Miller et al., 1997; Santelli et al., 2000).

Also consistent with previous research, youth whose mothers began childbearing at early ages, youth who resided in non-intact families, and youth whose mothers were less educated were likely to have earlier sexual onset (Lammers et al., 2000; Miller et al., 1997; Murry McBride, 1996; Oman et al., 2005; Paul et al., 2000; Santelli et al., 2000; Udry et al., 1995). Finally, also consistent with prior research on the effects of parental process, youth who experienced more frequent maternal monitoring and less maternal rejection were likely to have initiated sexual intercourse at later ages than those who were less heavily monitored and experienced more rejection (Capaldi et al., 1996; Danziger, 1995; French and Dishion, 2003; Whitbeck et al., 1999).

Overall, we find support for interlocking pathways and linked lives within the life course perspective (Elder, 1995). That is, the structural characteristics of grandmother's (G1's) are associated with mother's (G2's) as well as adolescent's (G3's) behavior, and as such, are associated with the timing of sexual onset among adolescent males and females. In other words, we find that the behaviors of previous generations continue to impact current generations thereby supporting the concept of linked lives, or the embeddedness of social relationships with kin across the life span. Additionally, we are able to demonstrate the intergenerational transmission (Elder et al., 1986) of social timing by showing how grandmother characteristics are associated with sexual onset via mother's characteristics. Finally, the importance of intergenerational transmission (Elder et al., 1986) is also supported because the experiences of early rejection and lower levels of monitoring from parents continue to affect the subsequent behavior of adolescents including the social timing of their sexual onset. These findings are important because they reveal the important impact that previous generations have on the subsequent behavior of later generations of adolescents.

The current study has many strengths. Because longitudinal NLSY data were employed, we were able to assess 
the etiology of adolescent sexual onset among a diverse sample of children from across the United States with an oversample of Hispanics/Latinos and Blacks. We were also able to follow children longitudinally from ages 12-13 until they were 17-18 using multiple reporters, thus allowing us to increase the validity of our findings. Finally, because of the nature of the research design, we were able to examine intergenerational transmission, linked lives, and social timing, thus providing valuable etiological insight into the timing of adolescent sexual onset.

Despite these many strengths, there are weaknesses. First, because of the survey design of the NLSY97, information on the target youths' fathers and grandfathers was not available. It is likely, however, that the characteristics and behaviors of male family members are important in the explanation of the timing of adolescent sexual onset. These associations should be examined in future research. Secondly, the variable representing the childbearing age of the grandmother (G1) measured the age at which the grandmother gave birth to the responding parent (G2), not the age at which they gave birth to their first child. Although this is not ideal and cannot be directly compared to the age of the mother (G2) at first birth, it is a reasonable measure of approximate childbearing age. Additionally, the childbearing age of the grandmother as well as grandmother's level of education were based on reports of the responding parent. As previously explained, approximately $16 \%$ of the cases included in the current analyses included parental reports given by someone other than a biological mother. In these cases, the information given by the responding parent regarding their mother does not necessarily pertain to the youth's maternal grandmother. Despite this, controlling for the relationship of the target youth to the responding parent did not reveal a significant effect on sexual onset. Third, because of the wording of the survey question, sexual intercourse with a same sex partner is impossible to identify. Additionally, this variable does not account for the experience of forced sex. It is possible that the first time youth engaged in sexual intercourse, it was against their will. Although this is an important consideration in any investigation of sexual behavior, the use of secondary data prohibited the measurement of this occurrence.

Despite these limitations, the results of the current analysis point to the importance of both distal and proximal structural factors, as well as parental process on the sexual behavior of adolescents. Although the sexual life of a young adult seems far beyond the reach of a grandmother's influence, the linked lives of grandmothers, their daughters, and their daughter's children may be more powerfully influential than previously thought. This research suggests that the legacy of the sexual practices of previous generations (mothers and grandmothers), as well as the structural conditions they experienced, demonstrate the linked lives these generations share and that intergenerational transmission is indeed relevant in the explanation of the age at which youth initiate sexual activity. Despite these findings, however, we are not implying that the sexual lives of adolescents are mapped out for them 30 years prior to their birth. Much to the contrary, our findings suggest that although both distal and proximal structural factors are important, parental process, in the form of maternal monitoring and rejection, plays an integral role in the formation of young people's sexual lives. Although we focus on structural and behavioral correlates of adolescent sexual onset, it is also possible that the timing of sexual debut may be passed from generation to generation via pubertal timing and/or temperament. With the advent and growing popularity of large multigenerational longitudinal data sets such as the NLSY, future research should consider these factors in the investigation of adolescent sexual behavior.

Our findings, which support the existence of intergenerational transmission, point to the need to take into account distal factors including grandmother characteristics in addition to the youth's characteristics and parenting practices when focusing on prevention of early sexual activity. Although structural characteristics, unlike parenting processes, cannot be changed, they can and need to be considered when designing prevention programs. The fact that early family histories create patterns for the next generation through their linked lives also suggests that prevention should not only target youth and adolescents but should also focus on the larger family network.

Sexual initiation at young ages has numerous implications for the health and well-being of adolescents in the United States. Individuals who are very young when they begin engaging in sexual intercourse are likely to be ill-prepared for the emotional and mental consequences of their actions. Youth who initiate sexual relations at young ages are likely to have diminished academic achievement and aspirations (Brooke et al., 1994; Martin et al., 2005; Schvaneveldt etal., 2001) and greater levels of depressive symptoms (Martin et al., 2005). Additionally, because only $63 \%$ of sexually active 9-12th graders in America reported using a condom the last time they had sex (Grunbaum et al., 2004), and because research has shown that sexually active young adolescents are less likely to use effective contraception than older adolescents (Mosher and McNally, 1991; Sonenstein et al., 1989) this group is at particularly high risk for sexually transmitted infections (STI's) and unintended pregnancy. Indeed, sexually active youth in the United States aged 15 to 24 acquired 9.1 million new STI's in 2000, which represents nearly one-half of all new infections during that year (Weinstock et al., 2004). Further, 34\% of American women become pregnant at least once before the age of 20 (National Campaign to Prevent Teen Pregnancy, 2004), and approximately eight in ten of these pregnancies are unintended (Henshaw, 1998). Clearly, a better understanding of the factors that predict the onset of sexual intercourse is crucial to producing prevention programs to reduce this risky behavioral pattern. 


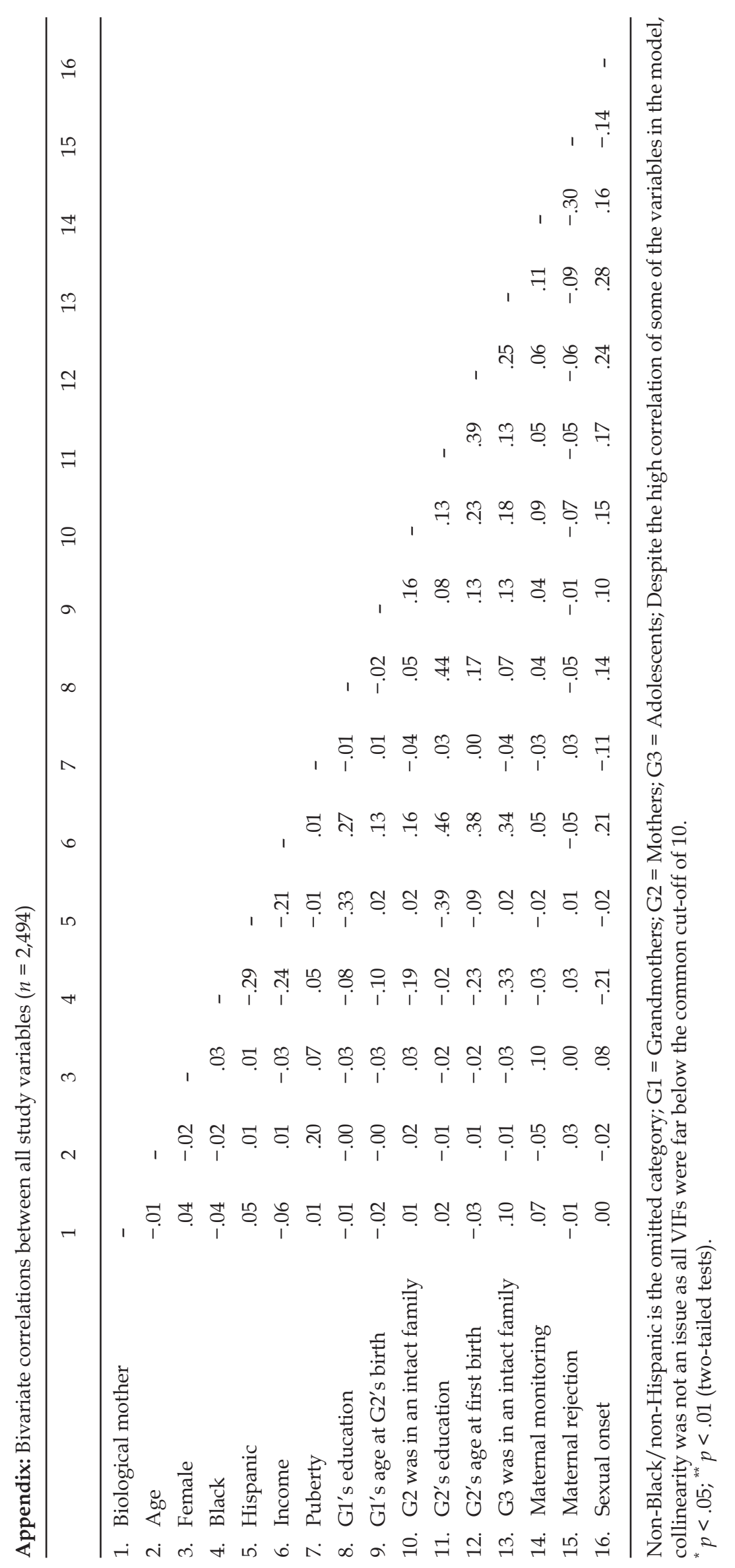




\section{References}

The Alan Guttmacher Institute (AGI) (2002) Sexual and reproductive health: Women and men. Retrieved February 19, 2006 from http://0-www.agi-usa.org.library.unl. edu/pubs/fb_10-02.html

Amato PR (1996) Explaining the intergenerational transmission of divorce. J Marriage Fam 58:628-640

Benda BB, Corwyn RF (1996) Testing a theoretical model of adolescent sexual behavior among rural families in poverty. Child Adolesc Soc Work J 13:469-494

Brooke JS, Balka EB, Abernathy T, Hamburg BA (1994) Sequence of sexual behavior and its relationship to other problem behaviors in African American and Puerto Rican adolescents. J Genet Psychol 155:107-114

Bumpass LL, Martin TC, Sweet JA (1991) The impact of family background and early martial factors on marital disruption. J Fam Issues 12:22-42

Capaldi DM, Crosby L, Stoolmiller M (1996) Predicting the timing of first sexual intercourse for at-risk adolescent males. Child Dev 67:344-359

Center for Human Resource Research (2002a) The National Longitudinal Surveys NLSY97 User's Guide, 2002. Retrieved February 19, 2006 from http://www.nlsinfo.org/ nlsy97/docs/97HTML00/97guide/toc.htm

Center for Human Resource Research (2002b) NLSY Codebook supplement main file round 1. Retrieved February 19, 2006 from ftp://ftp.chrr.ohio-state.edu/pub/usersvc/ NLSY97/NLSY97Rnd6CodebookSupplement/Round6CS/ maincstoc.htm

Centers for Disease Control and Prevention (2004) STD Surveillance 2004 Adolescents and Young Adults. Retrieved February 20, 2006 from http://0-www.cdc.gov.library.unl. edu/std/stats/adol.htm

Chapple CL, Tyler KA, Bersani B (2005) Child neglect and adolescent violence: Examining the effects of self-control and peer rejection. Violence Vict 20:39-53

Danziger SK (1995) Family life and teenage pregnancy in the inner-city: Experiences of African-American youth. Child Youth Serv Rev 17:183-202

Durbin M, DiClemente RJ, Siegel D, Krasnovsky F, Lazarus N, Camacho T (1993) Factors associated with multiple sex partners among junior high school students. J Adolesc Health 14:202-207

Elder GH (1996) Human lives in changing societies: Life course and developmental insights. In Cairns RB, Elder GH, Costello EJ (eds) Developmental science. Cambridge University Press, New York, pp. 31-62

Elder GH (1995) The life course paradigm: Social change and individual development. In Moen P, Elder GH, Lüscher K (eds) Examining lives in context: Perspectives on the ecology of human development. American Psychological Association, Washington, DC, pp. 101-139

Elder G, Caspi A, Downey G (1986) Problem behavior and family relationships: Life course and intergenerational themes. In Sorensen A, Weinert F, Sherrod L (eds) Human development: Interdisciplinary perspectives. Erlbaum, Hillsdale, NJ, pp. 293-340

Ensminger ME (1990) Sexual activity and problem behaviors among black, urban adolescents. Child Dev 61:2032-2046
Flannery DJ, Rowe DC, Gulley BL (1993) Impact of pubertal status, timing, and age on adolescent sexual experience and delinquency. J Adolesc Res 8:21-40

French DC, Dishion TJ (2003) Predictors of early initiation of sexual intercourse among high-risk adolescents. J Early Adolesc 23:295-315

Grunbaum JA, Kann L, Kinchen S, Ross J, Hawkins J, Lowry R, Harris WA, McManus T, Chyen D, Collins J (2004) Youth risk behavior surveillance-United States, 2003. Retrieved February 19, 2006 from http:/ / 0-www.cdc.gov.library.unl. edu/mmwr/preview/mmwrhtml/ss5302a1.htm

Harvey SM, Spigner C (1995) Factors associated with sexual behavior among adolescents: A multivariate analysis. Adolescence 30:253-264

Haynie DL, Piquero AR (2006) Pubertal development and physical victimization in adolescence. J Res Crime Delinquency 43:3-35

Hearn KD, O'Sullivan LF, Dudley CD (2003) Assessing reliability of early adolescent girls' reports of romantic and sexual behavior. Arch Sex Behav 32:513-521

Henshaw SK (1998) Unintended pregnancy in the United States. Fam Plann Perspect 30:24-29

Joreskog KG (1999, June 22). How large can a standardized coefficient be? Retrieved December 18, 2006, from www.ssicentral.com/lisrel/techdocs/HowLargeCanaStandardizedCoefficientBe.pdf

Kowaleski-Jones L, Mott FL (1998) Sex, contraception and childbearing among high-risk youth: Do different factors influence males and females? Fam Plann Perspect 30:163-169

Koyle PFC, Jensen LC, Olsen J, Cundick B (1989) Comparison of sexual behaviors among adolescents having an early, middle, and late first intercourse experience. Youth Soc 20:461-475

Ku L, Sonenstein FL, Pleck JH (1993) Factors influencing first intercourse for teenage men. Public Health Rep 108:681-694

Lammers C, Ireland M, Resnick M, Blum R (2000) Influences on adolescents' decisions to postpone onset of sexual intercourse: A survival analysis of virginity among youths aged 13 to 18 years. J Adolesc Health 26:42-48

Lauritsen J (1994) Explaining race and gender differences in adolescent sexual behavior. Soc Forces 72:859-883

Longmore MA, Manning WD, Giordano PG (2001) Preadolescent parenting strategies and teens' dating and sexual initiation: A longitudinal analysis. J Marriage Fam 63:322-335

Longmore MA, Manning WD, Giordano PC, Rudolph JL (2004) Self-esteem, depressive symptoms, and adolescents' sexual onset. Soc Psychol Q 67:279-295

Manlove J (1997) Early motherhood in an intergenerational perspective: The experiences of a British cohort. J Marriage Fam 59:263-279

Martin A, Ruchkin V, Caminis A (2005) Early to bed: A study of adaptation among sexually active urban adolescent girls younger than age sixteen. J Am Acad Child Adolesc Psychiatry 44:358-367

Maynard RA (1996) Kids having kids: A Robin Hood Foundation special report in the costs of adolescent childbearing. Robin Hood Foundation, New York

Miller BC, Norton MC, Curtis T, Hill EJ, Schvaneveldt P, Young MH (1997) The timing of sexual intercourse among adolescents: Family, peer, and other antecedents. Youth Soc 29:54-83 
Miller BC, Norton MC, Fan X, Christopherson CR (1998) Pubertal development, parental communication, and sexual values in relation to adolescent sexual behaviors. J Early Adolesc 18:27-52

Mosher WD, McNally JW (1991) Contraceptive use at first premarital intercourse: United States, 1965-1988. Fam Plann Perspect 23:108-116

Mott FL, Fondell MM, Hu PN, Kowaleski-Jones L, Menaghan EG (1996) The determinants of first sex by age 14 in a highrisk adolescent population. Fam Plann Perspect 28:13-18

Murry McBride V (1996) An ecological analysis of coital timing among middle-class African American adolescent females. J Adolesc Res 11:261-279

Muthén LK, Muthén BO (2004) Mplus user's guide, 3rd edn. Muthén and Muthén, Los Angeles, CA

National Campaign to Prevent Teen Pregnancy (2004) Factsheet: How is the $34 \%$ statistic calculated? National Campaign to Prevent Teen Pregnancy, Washington, DC

O'Donnell L, O'Donnell CR, Stueve A (2001) Early sexual initiation and subsequent sex-related risks among urban minority youth: The reach for health study. Fam Plann Perspect 33:268-276.

Oman RF, Vesely SK, Aspy CB (2005) Youth assets and sexual risk behavior: The importance of assets for youth residing in one-parent households. Perspect Sex Reprod Health 37:25-31

Paul C, Fitzjohn J, Herbison P, Dickson N (2000) The determinants of sexual intercourse before age 16. J Adolesc Health 27:136-147

Rafaelli M, Crockett LJ (2003) Sexual risk taking in adolescence: The role of self-regulation and attraction to risk. Dev Psychol 39:1036-1046

Ream GL, Savin-Williams RC (2005) Reciprocal associations between adolescent sexual activity and quality of youthparent interactions. J Fam Psychol 19:171-179

Rodgers KB (1999) Parenting processes related to sexual risktaking behaviors of adolescent males and females. J Marriage Fam 61:99-109
Romer D, Black M, Ricardo I, Feigelman S, Kaljee L, Galbraith J, Neshir R, Hornik RC, Stanton B (1994) Social influences on the sexual behavior of youth at risk for HIV exposure. Am Jo Public Health 84:977-985

Rosenberg M, McCullough BC (1981) Mattering: Inferred significance and mental health among adolescents. Res Community Mental Health 2:163-182

Santelli JS, Lowry R, Brener ND, Robin L (2000) Adolescent sexual behavior: Estimates and trends from four nationally representative surveys. Fam Plann Perspect 32:156-165

Schvaneveldt PL, Miller BC, Berry EH, Lee TR (2001) Academic goals, achievement, and age at first sexual intercourse: Longitudinal, bidirectional influences. Adolescence 36:767-787

Sonenstein FL, Pleck JH, Ku LC (1989) Sexual activity, condom use, and AIDS awareness among adolescent males. Fam Plann Perspect 21:152-158

Steinberg L (2002). Adolescence. McGraw-Hill, New York, NY

Tubman JG, Windel M, Windle RC (1996) The onset of crosstemporal patterning of sexual intercourse in middle adolescence: Prospective relations with behavioral and emotional problems. Child Dev 67:327-343

Udry JR, Kovenock J, Morris NM, Van Den Berg BJ (1995) Childhood precursors of age at first intercourse for females. Arch Sex Behav 24:329-337

Underwood LE, Van Wyk JJ (1992) Normal and aberrant growth. In Wilson JD, Foster DW (eds) Williams textbook of endocrinology, 8th edn. W.B. Saunders, Philadelphia, pp. 1079-1138

Upchurch DM, Lillard LA, Aneshensel CS, Fang Li N (2002) Inconsistencies in reporting the occurrence and timing of first intercourse among adolescents. J Sex Res 39:197-206

Weinstock H, Berman S, Cates W (2004) Sexually transmitted diseases among American youth: Incidence and prevalence estimates, 2000. Perspect Sex Reproduct Health 36:6-10

Whitbeck LB, Yoder KA, Hoyt DR, Conger R (1999) Early adolescent sexual activity: A developmental study. J Marriage Fam 61:934-946 